\title{
ARTICLES
}

\section{A STUDY TO EVALUATE THE ADEQUACY OF MODERATE BREATHING ON WORRY AMONG LADIES WITH HYPERTENSION IN A CHOSEN VILLAGE IN THIRUVALLUR REGION NEAR CHENNAI CITY}

Mrs Beula J*I Dr. Raj Rani**

* Research Scholar, Himalayan University, Itanagar, Arunachal Pradesh, India.

** Research Supervisor, Himalayan University, Itanagar, Arunachal Pradesh, India. DOI: http://doi.org/10.47211/tg.2020.v07i03.008

\begin{abstract}
It is an investigation to evaluate the adequacy of moderate breathing on worry among ladies with hypertension in a chosen village, in Thiruvallur region adjacent to Chennai city. Objective: The principal goal of the investigation was to survey the adequacy of moderate breathing on worry among ladies with hypertension in a chosen town in the Thiruvallur area of Tamil Nadu. Methods: Quasi-trial, one gathering pre-and post-test configuration was utilised in the current investigation. The current examination was done in a chosen town in Tamil Nadu. The sample included 30 ladies with hypertension, those that satisfied the consideration measures. Information was gathered from the members by making use of a self-controlled inquiry to gather the segment of information and an altered apparent pressure scale was used to evaluate the circulatory strain. At that point, 5 minutes of profound breathing activity (6 breaths per each minute in an agreeable position) was allowed twice every day with the immediate oversight for seven days. Results: The outcome demonstrated that pre-and post-test mean contrast was 8 with S.D of 2.20 and paired $t$ value $=3.05$, which was found factually noteworthy at $p<0.05$. Consequently, the score demonstrated that there was critical mean contrast between the pre-and post-test anxiety at $p<0.05$ level. It was presumed that the moderate breathing has an impact on controlling worry among ladies with hypertension.
\end{abstract}

Keywords: Slow breathing, stress, moderate breathing, hypertension.

\section{ABOUT AUTHORS:}

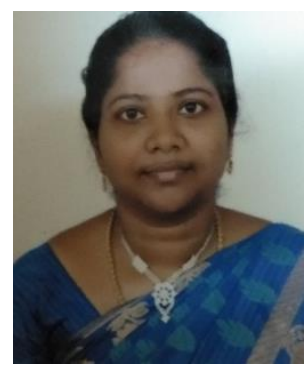

Author Mrs. Beula J is Research Scholar in Himalayan University, Itanagar, Arunachal Pradesh, India. She has attended various Seminars and conferences.

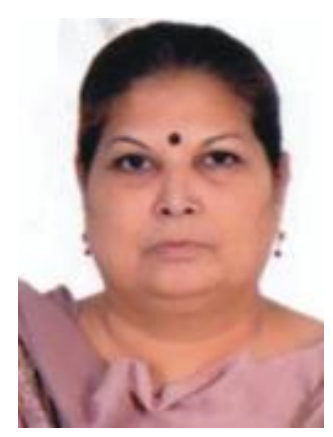

Author Dr. Rajrani is Ph.D. Guide at Himalayan University, Itanagar, Arunachal Pradesh, India. She is active researcher with many publications in her name. She has attended and organised various National and International conferences. 


\section{INTRODUCTION}

Over the world, the level of pressure is on the increase. Different examinations demonstrate the degree of worry among all ladies is increasing. It is around $85 \%$ of grown-ups are found worried normally. Nationally, the level of pressure in $89 \%$ of individuals is under strain.

A variety of occasions and conditions cause us to encounter pressure, including; routine issues, (for example, getting the family out the entryway toward the beginning of the day, or managing a troublesome colleague), onetime occasions that modify our carries on with, (for example, moving, marriage, labour, or evolving employments) and continuous long haul requests, for example, managing an interminable infection or thinking about a kid or wiped out relative). In spite of the fact that various individuals may encounter a similar kind of occasions, every one of them will encounter that occasion in a one of a kind way. That is, a few people are more helpless against getting worried than others are, in a given circumstance. An occasion of being stalled in a rush hour gridlock may make one individual become exceptionally worried while it probably will not influence someone else much at all. Even 'great' stressors, for example, getting hitched can affect people in an unexpected way.

Presently a day's expanding number of ladies is looking with the undertaking of shuffling the jobs of mother and representative. In an examination, it was discovered that married ladies performed around $64 \%$ of the aggregate sum of a family unit's work and that their commitment when contrasted with married men was especially high when it came to work inside (78\%) and kid care (67\%). Ladies not prepared to deal with themselves by their own, consistently consider their family. So, the specialist figured a basic unwinding by giving a breathing activity will decreases the feeling of anxiety among them.

The commonness of worry among ladies overall bogus inside the range from 19.6 to $66.2 \%$ demonstrated related side effect were additionally evaluated. It shows that about $30 \%$ ladies experienced back torment $28 \%$ grievances of stress 22.05 feels weariness and $30 \%$ experienced cerebral pain. Hypertension is one of the most notable across the board ailments, impacting individuals and is a critical danger factor for heart, kidney, and veins.

\section{OBJECTIVES}

- To evaluate the pre- and post-test levels of worry among the ladies with hypertension

- To assess the efficacy of moderate breathing activity on worry among the ladies with hypertension.

\section{NULL HYPOTHESIS}

H01: There is no critical distinction between the pre- and the post-test levels of worry among ladies with hypertension.

\section{METHODOLOGY}

The methodology used in the assessment was quantitative exploration approach. The pro grasped a semi test one gathering pre and post-test structure for this current examination. The assessment was driven in a chose town in Thiruvalur district. The model size of the assessment was 30, non-probability purposive examining technique was used to pick the members the substance authenticity of the gadget was gotten from the nursing pros. The analyst advanced toward every model who fulfilled the thought models, brief introduction about the examination was given, and the classification was guaranteed to all members, and taught about moderate breathing 6 breaths/mt two times every day for persistent $5 \mathrm{mts}$ in a happy with sitting situation for seven days with the immediate oversight. A comparable procedure was followed for all the members in an equivalent setting.ad the post test was finished by utilizing a similar device which was utilized for pre-test.

\section{RESULTS}

The information finding uncovered that concerning age dominant part of them 17 (56.6\%) were in the age gathering of over 31-40 years. 7 (23.3\%) were in the age gathering of 60years, $4(13.3 \%)$ were in the age gathering of 51 - 60 years, and 2 (6.6\%) were in the age gathering of $41-50$ years. As to dominant part of them 18 (60\%) were unskilled $6(20 \%)$ were essential instruction $5(16.6 \%)$ were graduates and 1 (3.3\%) were post graduate. Regarding occupation greater part of the ladies $18(60 \%)$ were housewives $2(6.6 \%)$ were in govt. division, 4 (13.3\%) were in private area 2 (6.6\%) were doing their own business and $10(3.3 \%)$ of them are accomplishing coolie work. With respect to pay 4 (13.3\%) were acquiring beneath RS 5000, 11 (36.6\%) were procuring RS 5001 10000, 7 (23.3\%) were gaining between RS 10001 - 15000, 2 (6.6\%) were winning between RS 15001 or more. 


\section{ARTICLES}

Concerning conjugal status 9 (30\%) were unmarried, 21 (70\%) were hitched, Considering the religion 28 (93.3\%) were Christian 2(6.6\%) were Hindu, considering the kind of family 19(63.3\%) were live in the family unit 11 (36.6) were lives in joined family. With respect to dietary example, $1(33.3 \%)$ were vegan $8(26.6 \%)$ were non veggie lover, $21(70 \%)$ were taking both. With respect to practice design larger part of them $27(90 \%)$ were not having the act of doing exercise $2(6.6 \%)$ doing exercise 30minutes day by day $1(3.3 \%)$ were doing 1 hour in seven days. As to the board of hypertension greater part of them 19 (63.3\%) were having the act of taking medicine alongside dietary administration, $5(16.6 \%)$ were followed just the dietary administration, $2(6.6 \%)$ were having every one of the three acts of dietary, $4(13.3 \%)$ were not following any of the administration.

As to length of hypertension $9(30 \%)$ were having hypertension for a half year to 1 years, $8(26.6 \%)$ were having hypertension 1-3 years, 4 (13.3\%) were having hypertension 3to 5 years, $9(3$ The above table shows that examination of pre-test and post-test level of worry among ladies with hypertension.

Assessment of Pre-Test and Post-Test Level of Stress among Women with Hypertension

\begin{tabular}{|l|c|c|c|c|c|c|}
\hline \multirow{2}{*}{} & \multicolumn{2}{|c}{ Mild } & \multicolumn{2}{c|}{ Stage 1 } & \multicolumn{2}{c|}{ Stage-2 } \\
\cline { 2 - 7 } & No & $\%$ & No & $\%$ & No & $\%$ \\
\hline Pre-test & 8 & $26.6 \%$ & 12 & $40.0 \%$ & 10 & $33.3 \%$ \\
\hline Post-test & 17 & $60.0 \%$ & 9 & $30.0 \%$ & 4 & $13.3 \%$ \\
\hline
\end{tabular}

The above table denotes the frequency and percentage distribution of pre-test and post-test levels of stress among women with hypertension.

Assessment of Effectiveness of Slow Breathing Exercise on Stress among Women with Hypertension

$\mathbf{N}=\mathbf{3 0}$

\begin{tabular}{|c|l|c|c|c|c|}
\hline \multicolumn{2}{|c|}{} & Mean & Mean difference & Standard deviation & Paired ' $t$ ' value \\
\hline \multirow{2}{*}{ STRESS } & Pre-test & 34 & \multirow{2}{*}{8} & 2.20 & \\
\cline { 2 - 3 } & Post-test & 26 & & 2.14 & 3.05 \\
\cline { 5 - 6 } & & &
\end{tabular}

As to relationship of post-test level of worry with the chose segment variable, the discoveries uncovered that there was no factual noteworthy affiliation was found with instruction, family pay, religion, history of doing customary exercise, term of hypertension.0\%) were having hypertension over 5 years. 


\section{ARTICLES}

\section{REFERENCES}

\section{BOOKS}

1. Arnold Bloom and Stephen Bloom, (1992). Medicine for nurses $\left(14^{\text {th }}\right.$ ed.). London: Churchill Livingstone Publication.

2. Artene, L. Polaski, Suzzanne, E. Tatro, (1996). Medical surgical nursing. Philadelphia: W.B. Saunders Company.

3. Bare G. Brenda, Smeltzer, C. Suzanne, (1996). Brunner and Suddarth's textbook of medical and surgical nursing ( $8^{\text {th }}$ ed.). Philadelphia: J.B. Lippincott Company.

4. Bijlani RL, et, al. (2010) Understanding Medical Physiology: A Textbook for Medical Students. 3rd Ed. New Delhi: Jaypee Brothers Publishers; p. 872.

5. Brunner and suddarth's "text book of medical surgical nursing" $10^{\text {th }}$ edition Lippincott Williams and wilkins publications pag.no.662-672

\section{JOURNALS}

1. Jennifer C. (2000) the effect of rhythmic breathing on blood pressure in hypertensive adults. Journal of undergraduate research1:78-98.

2. Khalsa S B. (2004) Yoga as a therapeutic intervention: A bibliometric analysis of published research studies. Indian J Physic Pharmacology. 48:269-85

3. Madan mohan T, et, al.( 2003) Review of Shavasana studies conducted at JIPMER. Yoga Mimamsa.; 35:26-34

4. Pal T. Et. al (2004) Effect of short-term practice of breathing exercises on autonomic functions in normal human volunteers. Indian J Med Res.; 120:115-21

5. Roberti J W, et al (2006). Further psychometric support for the 10-item version of the perceived stress scale. J Coll Couns.; 9:135-47

6. Ross A. \& Thomas S. (2010). The health benefits of yoga and exercise: a review of comparison studies. The journal of alternative and complementary medicine, 16(1), 3-12.

7. Saih LO. A longitudinal study of perceived level of stress, coping and self-esteem of undergraduate students. Journal of advanced nursing 2002:39(2); 119-126.

8. Sharma V K, Trakroo M, Subramaniam V, Raja jayakumar M, Bhavani A B, Sahai A. Effect of slow pranayama on perceived stress in young health case student. IntYoga.2013:3;6;104-10 